\title{
Adenocarcinoma pulmonar associado à infecção por Mycobacterium sp. em vaca - relato de caso
}

[Pulmonary adenocarcinoma associated with infection by Mycobacterium sp. in a cow-case report]

\author{
N.G.A. Medeiros ${ }^{1}$, M.T.S. Frade ${ }^{1}$, E.P.F. Souto ${ }^{1 *}$, M.A. Melo ${ }^{1}$, G.M.N. Aguiar ${ }^{2}$, \\ S.S. Azevedo ${ }^{1}$, M.B. Heinemann ${ }^{3}$, A.F.M. Dantas ${ }^{1}$ \\ ${ }^{1}$ Programa de pós-graduação - Universidade Federal de Campina Grande - Patos, Paraíba \\ ${ }^{2}$ Unidade Acadêmica de Viçosa - Universidade Federal de Alagoas - Viçosa, AL \\ ${ }^{3}$ Faculdade de Medicina Veterinária e Zootecnia - Universidade de São Paulo - São Paulo, SP
}

\begin{abstract}
RESUMO
Descrevem-se os aspectos clínicos, anatomopatológicos, imuno-histoquímicos, microbiológicos e moleculares de um caso de adenocarcinoma pulmonar associado à infecção por Mycobacterium sp. em uma vaca. O animal apresentou hiporexia, emagrecimento, vocalizações, postura ortopneica, ingurgitamento da jugular, estase venosa positiva, gemido expiratório e morte. Na necropsia, os pulmões estavam aumentados e apresentavam, na superfície pleural, nódulos branco-amarelados, firmes, multifocais a coalescentes, interpostos por áreas avermelhadas. Ao corte, os nódulos aprofundavam-se ao parênquima e possuíam múltiplos focos de aspecto caseoso e friável e áreas de mineralização. O saco pericárdico e os linfonodos traqueobrônquicos, ilíacos, lombares aórticos e mamários apresentavam lesões semelhantes. Histologicamente, observou-se neoformação carcinomatosa associada a áreas multifocais de necrose e mineralização. As células neoplásicas foram fortemente imunomarcadas pelo anticorpo antipancitoqueratina AE1/AE3. Na cultura microbiológica de fragmentos dos pulmões, houve crescimento de colônias bacterianas compatíveis com micobactérias atípicas. O sequenciamento molecular submetido ao BLASTn identificou o Mycobacterium sp. WCM 7299 (ID: gb|KJ873243.1|).
\end{abstract}

Palavras-chave: doença de bovino, pneumopatia, neoplasma, Mycobacterium

\begin{abstract}
The clinical, anatomopathological, immunohistochemical, microbiological and molecular aspects of a case of pulmonary adenocarcinoma associated with infection by Mycobacterium sp. in a cow are described. The animal presented hyporexia, weight loss, vocalizations, orthopneic posture, jugular engorgement, positive venous stasis, expiratory groaning and death. At necropsy, the lungs were enlarged and presented firm, multifocal to coalescent yellowish nodules, interposed by reddish areas on the pleural surface. At cut, the nodules deepened to the parenchyma and had multiple foci of caseous and friable appearance and areas of mineralization. The pericardial sac and tracheobronchial, iliac, aortic lumbar and mammary lymph nodes showed similar lesions. Histologically, a carcinomatous neoformation, associated with multifocal areas of necrosis and mineralization, was observed. Neoplastic cells were strongly immunolabelled by antiPanCytokeratin antibody AE1/AE3. Microbiological culture of lung fragments showed growth of bacterial colonies compatible with atypical mycobacteria. Molecular sequencing submitted to BLASTn identified the Mycobacterium sp. WCM 7299 (ID: gb|KJ873243.1|).
\end{abstract}

Keywords: cattle disease, pneumopathy, neoplasm, Mycobacterium

Recebido em 27 de dezembro de 2019

Aceito em 13 de abril de 2020

*Autor para correspondência (corresponding author)

E-mail: erickplatini@gmail.com 


\section{INTRODUÇÃO}

Os tumores primários do pulmão são considerados raros em bovinos e, quando ocorrem, são geralmente adenocarcinomas (Viott et al., 2010). No Brasil, casos foram descritos por Viott et al. (2010), Lucena et al. (2011), Sousa et al. (2014) e Andrade Neto et al. (2019).

De acordo com a Agência Internacional de Pesquisa em Câncer, da Organização Mundial de Saúde, há evidências de que infecções crônicas por alguns tipos de vírus, bactérias e parasitas estão associadas ao desenvolvimento de neoplasias em humanos, como infecção por Helicobacter pylori e carcinoma gástrico; vírus da hepatite B e C e hepatocarcinomas; Opisthorchis viverrini e carcinoma de vias biliares; Schistosoma haematobium e carcinoma de bexiga (Brasil, 2006); e Mycobacterium spp. com adenocarcinomas pulmonares (Silva et al., 2013; Wu et al., 2011).

Na medicina veterinária, têm sido relatados casos de adenocarcinoma gástrico em chinchila associado à infecção por $H$. pylori (Lucena et al., 2012) e colangiocarcinomas em gatas associados à Platynosomum fastosum (Andrade et al., 2012). Entretanto, não foram identificados casos de neoplasias pulmonares em bovinos associados a infecções por Mycobacterium spp. Objetiva-se descrever um caso de adenocarcinoma pulmonar em uma vaca associado à infecção por Mycobacterium sp.

\section{RESULTADOS}

Uma vaca mestiça, com 10 anos de idade, foi atendida no Hospital Veterinário Universitário da Universidade Federal de Campina Grande, Campus de Patos, Paraíba, apresentando hiporexia, emagrecimento e vocalizações há aproximadamente 30 dias. Ao exame clínico, observou-se postura ortopneica, ingurgitamento da veia jugular, estase venosa positiva, gemido expiratório e mucosas oculares levemente pálidas. Suspeitou-se de tuberculose ou neoplasia, mas, antes da adoção de medidas terapêuticas, o animal morreu.

Na necropsia, observou-se estado corporal magro, edema de subcutâneo e discreta ascite e hidrotórax. Os pulmões estavam moderadamente aumentados, com nódulos multifocais a coalescentes amarelado-brancacentos e firmes, interpostos por áreas avermelhadas. Ao corte, os nódulos se aprofundavam ao parênquima, rangiam ao corte (mineralização) e apresentavam múltiplos focos de aspecto caseoso e friável (Fig.1A). Os linfonodos traqueobrônquicos, ilíacos, lombares aórticos e mamários estavam difusamente aumentados de volume. Ao corte, observou-se perda da distinção corticomedular, coloração branco-amarelada e múltiplos focos firmes e brancacentos (mineralização) (Fig.1B), semelhantes aos achados observados nos pulmões. $\mathrm{O}$ pericárdio parietal também apresentava nodulações multifocais firmes, branco-amareladas, que mediam aproximadamente $0,5 \mathrm{~cm}$ de diâmetro.

Os tecidos coletados foram fixados em formol a $10 \%$ tamponado, clivados, processados rotineiramente, seccionados em $3 \mu \mathrm{m}$ e corados por hematoxilina e eosina (HE). Secções histológicas selecionadas foram submetidas à coloração histoquímica especial de Ziehl-Neelsen $(\mathrm{ZN})$.

Para confirmação da proliferação epitelial maligna, foi realizada técnica imuno-histoquímica (IHQ). Secções histológicas de $4 \mu \mathrm{m}$ foram desparafinizadas em xilol, hidratadas em concentrações decrescentes de etanol e lavadas em água destilada. Em seguida, os tecidos foram submetidos à recuperação antigênica pelo calor em solução de citrato $10 \mathrm{mM}(\mathrm{pH} \mathrm{6,0)}$ na panela de pressão (Pascal, Dako). Posteriormente, as lâminas foram colocadas em temperatura ambiente por 20 minutos para resfriamento e lavagem em água deionizada.

Após a recuperação antigênica, foi realizado o bloqueio da peroxidase endógena com a imersão das lâminas em peróxido de hidrogênio pronto para uso (Peroxide Block, Cell Marque, 925B-09). Após essa etapa, os cortes foram lavados em solução Tris ( $\mathrm{pH} 7,4)$ e, a seguir, os sítios inespecíficos foram bloqueados com solução bloqueadora de reação inespecífica (Protein Block Serum-Free, Dako X0909). Foi realizada incubação com anticorpo primário (antipancitoqueratina, clone AE1/AE3) por 18 horas, a $4^{\circ} \mathrm{C}$. Como sistema de amplificação e detecção, utilizou-se o EnVision Dual Link (Dako, K4065) e o cromógeno diaminobenzidina (Dako, K3468). As lâminas foram contracoradas com hematoxilina de Harris. Como controle 
positivo, foi utilizada a pele de bovino, e o controle negativo foi obtido pela omissão do anticorpo primário. Para obtenção do último, foi empregado apenas o diluente de anticorpo.

Fragmentos de pulmão e linfonodos foram congelados a $-80^{\circ} \mathrm{C}$ e enviados ao Laboratório de Zoonoses Bacterianas da Faculdade de Medicina Veterinária e Zootecnia da USP para isolamento e identificação de Mycobacterium bovis. No isolamento as amostras passaram por descontaminação seguida da semeadura nos meios de cultura Lowenstein-Jensen e Stonebrink-Leslie e incubação a $37^{\circ} \mathrm{C}$ por 60 a 90 dias. Para identificação do agente etiológico, foram utilizadas as técnicas TB Multiplex PCR e RD Multiplex PCR. A última etapa realizada foi o sequenciamento do gene da HSP65 com submissão ao BLASTn.

$\mathrm{Na}$ avaliação histopatológica do pulmão, observou-se uma neoformação densamente celular, mal delimitada e expansiva, composta por células epiteliais malignas, assumindo arranjos em papilas e ninhos, frequentemente com áreas centrais de necrose e mineralização (Fig.1C e D), e sustentadas por moderado estroma fibrovascular. As células neoplásicas eram cuboides, com citoplasma eosinofílico variando de escasso a moderado, de limites pouco evidentes, núcleo redondo ou ovalado, com a cromatina vesiculosa e um a dois nucléolos. Verificou-se moderado pleomorfismo, caracterizado por acentuada anisocariose, além de figuras mitóticas (1 a 2 por campo de maior aumento[400x]) e êmbolos de células neoplásicas no lúmen de vasos sanguíneos e linfáticos. Entre os nódulos neoplásicos, observou-se abundante proliferação de tecido conjuntivo e edema nos espaços alveolares. Pela IHQ, observou-se forte imunomarcação das células epiteliais malignas, em marrom, pelo anticorpo antipancitoqueratina (Fig.1E).

Os linfonodos, macroscopicamente alterados, e os nódulos no pericárdio parietal apresentavam proliferações neoplásicas similares às descritas no pulmão, caracterizando-se como metástases. Nos linfonodos, a proliferação neoplásica ocupava quase todo o parênquima, com extensas áreas de necrose e mineralização. $\mathrm{Na}$ coloração histoquímica especial de $\mathrm{ZN}$, não foram observadas bactérias ácido-álcool resistentes nas amostras pesquisadas.

A cultura microbiológica revelou a presença de colônias com crescimento lento e pigmentação amarelo-alaranjada, rugosas e secas (Fig.1F), características de micobactérias atípicas, provavelmente do grupo II, de acordo com a descrição realizada por Quinn et al. (2004). Na TB Multiplex PCR e RD Multiplex PCR, não houve amplificação de DNA de $M$. bovis nas colônias isoladas. $\mathrm{O}$ fragmento amplificado foi sequenciado e submetido a análise através da Plataforma BLASTn do NCBI (https://blast.ncbi.nlm.nih.gov/Blast.cgi),

verificando identidade de $100 \%$ (e-value 0.0$) \mathrm{com}$ o Mycobacterium sp. WCM 7299 (ID: gb|KJ873243.1|), uma espécie de micobactéria não-tuberculosa.

\section{DISCUSSÃO}

O diagnóstico de adenocarcinoma pulmonar associado à infecção por Mycobacterium sp. foi estabelecido com base nos achados clínicos, anatomopatológicos, imuno-histoquímicos, microbiológicos e moleculares. Os tumores primários do pulmão são bastante raros em bovinos, com pesquisas em abatedouros que mostram de dois a 20 casos por milhão de bovinos (Wilson, 2016). O adenocarcinoma parece ser a neoplasia primária mais frequentemente diagnosticada (Wilson, 2016).

Atualmente, reconhece-se uma associação entre as infecções por Mycobacterium spp. e o desenvolvimento de neoplasias pulmonares em seres humanos (Wu et al., 2011). Acredita-se que a incidência de neoplasias pulmonares em pessoas com tuberculose pode aumentar em até $1,8 \mathrm{vez}$ (Liang et al., 2009). No Brasil, Viott et al. (2010), Lucena et al. (2011), Sousa et al. (2014) e Andrade Neto et al. (2019) diagnosticaram casos de adenocarcinoma pulmonar em vacas adultas, mas não estabeleceram correlação com infecções por Mycobacterium spp. 

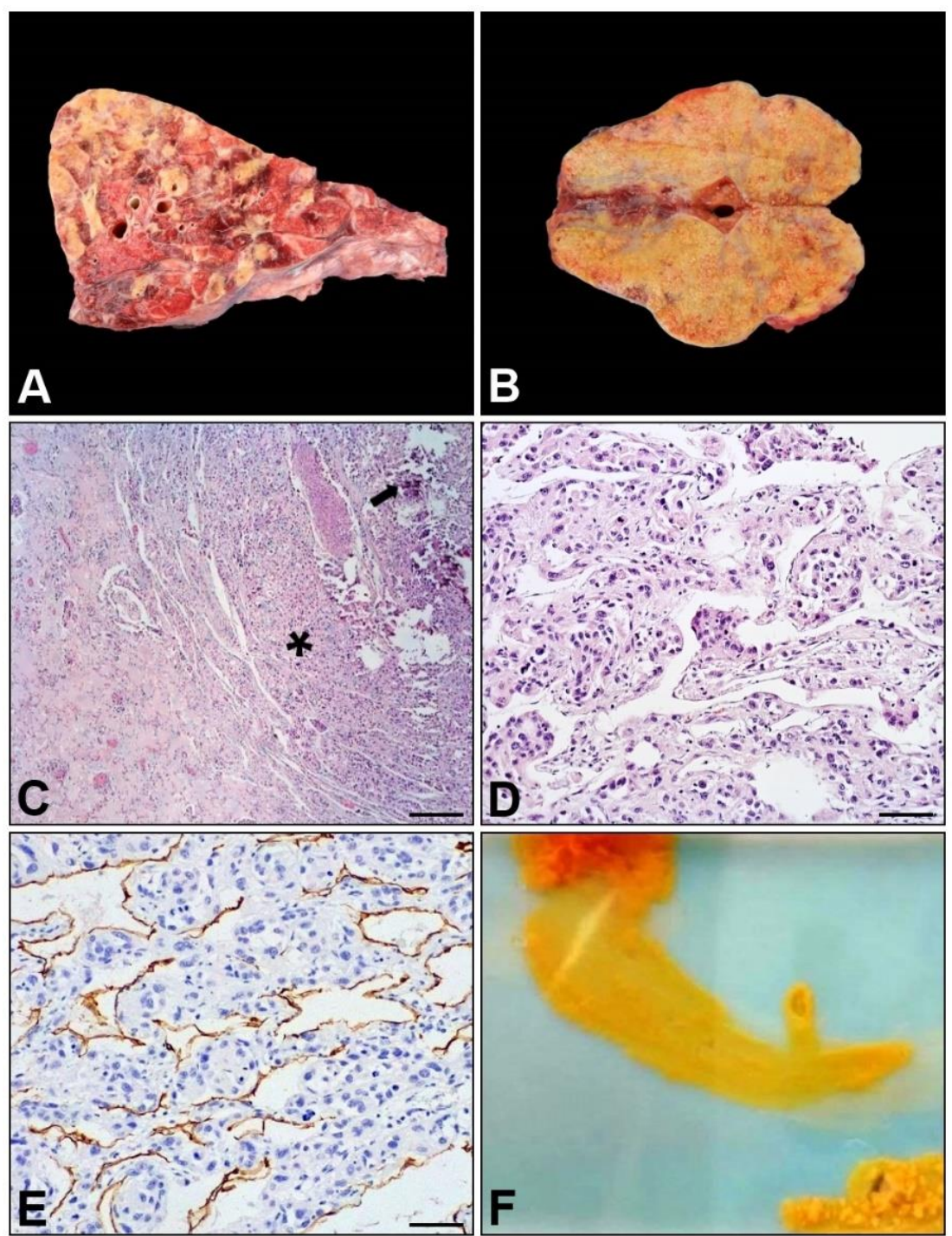

Figura 1. Adenocarcinoma pulmonar associado à infecção por Mycobacterium sp. em vaca. A) Pulmão, superfície de corte. Nódulos amarelados, multifocais a coalescentes, interpostos por áreas avermelhadas. B) Linfonodo traqueobrônquico, superfície de corte. Aumentado de tamanho e com nódulos amarelados, multifocais a coalescentes, sem distinção corticomedular. C) Fotomicrografia do pulmão. Proliferação neoplásica (asterisco) com área central de necrose e mineralização (seta). HE [Bar $=100 \mu \mathrm{m}]$. D) Fotomicrografia do pulmão. Células epiteliais malignas assumindo arranjo papilar, com moderado pleomorfismo. HE [Bar $=50 \mu \mathrm{m}]$. E) Fotomicrografia do pulmão. Forte imunomarcação positiva das células epiteliais malignas em marrom. IHQ, pancitoqueratina [Bar $=50 \mu \mathrm{m}]$. F) Cultivo microbiológico. Colônias bacterianas amarelo-alaranjadas características de micobactérias atípicas.

A relação entre inflamação crônica e neoplasias parece estar bem estabelecida, mas a relação entre tuberculose e neoplasias não está compreendida. Pacientes com neoplasias estão vulneráveis a desenvolverem tuberculose ativa por causa da imunossupressão ocasionada pela caquexia e por quimioterapias agressivas (Harikrishna et al., 2012). No entanto, a inflamação crônica e as cicatrizes da tuberculose podem levar ao desenvolvimento de neoplasias, pois, durante o desenvolvimento do granuloma, ocorre um desequilíbrio entre o tecido e os agentes que o danificam, o que pode causar danos ao material genético das células, predispondo-as à transformação maligna (Russell, 2007). 
Tanto a insuficiência respiratória quanto a cardíaca, identificadas durante o exame clínico, provavelmente foram decorrentes do aumento da resistência ao influxo sanguíneo no parênquima pulmonar pela presença dos nódulos neoplásicos. Além disso, é provável que tenha ocorrido comprometimento da drenagem linfática intrapulmonar. As lesões multinodulares com aspecto caseoso e áreas de mineralização nos pulmões sugeriram o diagnóstico macroscópico de tuberculose. Contudo, na histopatologia foi visualizada uma proliferação neoplásica carcinomatosa, compatível com adenocarcinoma pulmonar. Geralmente esses tumores apresentamse como nódulos sólidos e com áreas centrais de necrose, que macroscopicamente remetem a granulomas de tuberculose (Caswell e Williams, 2016).

Os tumores primários do pulmão devem ser diferenciados ainda de lesões neoplásicas metastáticas, que são achados frequentes em carcinomas presentes em outros tecidos (Wilson, 2016). É interessante notar que, além das lesões pulmonares, foram identificadas metástases para linfonodos, regionais e distantes, e a face externa do saco pericárdico. Tumores avançados podem causar metástases por vias hematógena, linfática e transcelômica; nesta última via, disseminando-se por toda a cavidade torácica (Wilson, 2016).

$\mathrm{Na}$ coloração histoquímica especial de $\mathrm{ZN}$ não foram identificadas bactérias ácido-álcool resistentes nas amostras pesquisadas, o que pode estar relacionado à baixa sensibilidade dessa técnica ante a escassez de bactérias em lesões crônicas (Estrada-Chavez et al., 2004). Contudo, os achados da cultura microbiológica, PCR e sequenciamento genético revelaram a presença de bactérias do gênero Mycobacterium sp. intralesionais, fornecendo evidências para uma associação entre a infecção e o desenvolvimento do adenocarcinoma pulmonar.

É importante considerar que se fazem necessários estudos mais abrangentes para identificar $\mathrm{o}$ efetivo papel dessas micobactérias atípicas na carcinogênese, bem como sua interferência nos resultados do teste de tuberculinização, utilizado para o controle e a erradicação da tuberculose bovina em todo o país.

As micobactérias atípicas geralmente infectam os animais de forma inaparente e sem induzir resposta inflamatória granulomatosa. Os animais podem funcionar como fonte de infecção ao homem e esses microrganismos podem causar reação cruzada com o $M$. tuberculosis e comprometer a interpretação da reação tuberculínica e a eficácia da vacina BCG (Vandiviere et al., 1981). Dessa forma, o diagnóstico dos animais infectados e a identificação de espécies de micobactérias atípicas representam dados relevantes para a saúde pública.

\section{CONCLUSÃO}

Os adenocarcinomas pulmonares são neoplasmas raros em bovinos e, quando diagnosticados, devem ser realizados testes microbiológicos e moleculares para identificação de micobactérias intralesionais, pois é provável que ocorra associação entre a infecção e a carcinogênese.

\section{AGRADECIMENTOS}

Ao CNPq, pela bolsa de produtividade (Processo no 309460/2017-4), e à colaboração da Faculdade de Medicina Veterinária e Zootecnia da Universidade de São Paulo.

\section{REFERÊNCIAS}

ANDRADE NETO, A.Q.; SOUTO, R.J.C.; CAJUEIRO, J.F.P. et al. Primary pulmonary adenocarcinoma in a cow. Acta Sci. Vet., v.47, p.1-6, 2019.

ANDRADE, R.L.; DANTAS, A.F.; PIMENTEL, L.A. et al. Platynosomum fastosum-induced cholangiocarcinomas in cats. Vet. Parasitol., vol. 190, p.277-280, 2012.

BRASIL. Ministério da Saúde. Secretaria de Atenção à Saúde. Instituto Nacional de Câncer. Coordenação de Prevenção e Vigilância. $A$ situação do câncer no Brasil. Rio de Janeiro: INCA, 2006, p.120.

CASWELL J.L.; WILLIAMS, K.J. Respiratory tract. In: MAXIE, M.G. (Ed.). Jubb, Kennedy, and Palmer's pathology of domestic animals. 6.ed. St. Louis: Elsevier, 2016, v.2, p.495-500.

ESTRADA-CHÁVEZ, C.; OTERO, F.D.; DÍAZ, C.A. et al. Concordancia de La PCR y métodos rutinarios para El diagnostico de tuberculose bovina. Vet. Mex., v.35, p.225-236, 2004. 
HARIKRISHNA, J.; SUKAVENI, V.; KUMAR, D.P.; MOHAN, A. Cancer and tuberculosis. $J$. Indian Acad. Clin. Med., v.13, p.142-144, 2012. In: _. Clinical veterinary microbiology. Mosby: Elsevier, 2004. p.156-169.

LIANG, H.Y.; LI, X.L.; YU, X.S. et al. Facts and fiction of the relationship between preexisting tuberculosis and lung cancer risk: a systematic review. Int. J. Cancer, v.125, p.2936-2944, 2009.

LUCENA, R.B.; RISSI, D.R.; KOMMERS, G.D. et al. A retrospective study of 586 tumors in Brazilian cattle. J. Comp. Pathol., v.145, p.20-24, 2011.

LUCENA, R.B.; RISSI, D.R.; QUEIROZ, D.M.M.; BARROS, C.S.L. Infiltrative gastric adenocarcinoma in a chinchilla (Chinchilla lanigera). J. Vet. Diag. Inv., v.24, p.797-800, 2012.

QUINN, P.J.; CARTER, M.E.; MARKEY, B.; CARTER, G.R. Mycobacterium species.

RUSSELL, D.G. Who puts the tubercle in tuberculosis? Nat. Rev. Microbiol., v.5, p.39-47, 2007.
SILVA, D.S.; VALENTINI JUNIOR, D.F.; MULLER, A.M. et al. Tuberculose pulmonar e cancer de pulmao: ocorrencia simultanea ou sequencial. J. Bras. Pneumol., v.39, p.484-489, 2013.

SOUSA, Z.D.; RIVERA, C.; LUIS, Q.C. et al. Pulmonary adenocarcinoma in cattle. Rev. Med. Vet. Zootec., v.19, p.4358-4363, 2014.

VANDIVIERE, H.M.; MELVIN, I.G.; NARAIN, R. et al. Profiles of skin test reactivity to antigens of various mycobacterial species in a human population and in experimental infections. Tubercle, v.61, p.245-257, 1981.

VIOTT, A.M.; LANGOHR, I.M.; VANNUCCI, F.A. et al. Adenocarcinoma pulmonary em um bovino. Cien. Rural, v.40, p.484-487, 2010.

WILSON, D.W. Tumors of the respiratory tract. In: MEUTEN, D.J. (Ed.). Tumors of domestic animals. 5.ed. United States: Raleigh, 2016. p.467-498.

WU, C.Y.; HU, H.Y.; PU, C.Y. et al. Pulmonary tuberculosis increases the risk of lung cancer: a population-based cohort study. Cancer, v.117, p.618-624, 2011. 